\title{
Autonomia apesar da dependência: a construção de uma antropologia dimensional no diálogo entre Frankl e Hartmann
}

\author{
Autonomydespite dependence: a dimensional anthropology construction \\ in the dialog between Frankl and Hartmann
}

http://dx.doi.org/10.5007/2178-4582.2016v50n2p478

Daniel Rubens Santiago da Silva

Úrsula Anne Matthias

Universidade Federal do Ceará, Fortaleza/CE, Brasil

\begin{abstract}
$\mathrm{O}$ artigo se trata de um estudo teórico onde são apresentados alguns pontos da Ontologia Dimensional de Nicolai Hartmann e a relação destes com a Antropologia Ontológico-Dimensional de Viktor Frankl. Além dos pontos em que se percebe uma clara influência de Hartmann no pensamento frankliano, procurou-se chegar a elementos do pensamento do primeiro para além daquilo que serve de fundamento à Logoterapia. Quanto à influência de Hartmann, concluiu-se pela centralidade de sua Ontologia Dimensional no esquema frankliano, atestada pelas concessões ao condicionamento "psicofísico" e pela crítica ao pandeterminismo e ao reducionismo. O resultado é a fórmula: "autonomia apesar da dependência". Quanto aos elementos que estão para além daquilo que serve de fundamento à Logoterapia, perceberamse possibilidades fecundas de diálogo, como por ocasião da discussão em torno da vida espiritual "a-temporal" e do "espírito objetivo".

Palavras-chave: Ontologia dimensional; Antropologia ontológico-dimensional; Logoterapia; Viktor Frankl; Nicolai Hartmann.
\end{abstract}

The article is about a theoretical study in which we present points of Nicolai Hartmann's Dimensional Ontology and their relation with Viktor Frankl's Ontological-Dimensional Anthropology. Besides the points in which Hartmann's clear influence in Frankl's thinking can be noticed, we sought to get to elements of the former's thinking to beyond what serves as basis to Logotherapy. As for Hartmann's influence, we came to the conclusion of the centrality of his Dimensional Ontology in the franklian structure, certified by the granting to "psycho-physical" conditioning and by the critic to pandeterminism and reductionism. The result is the formula: "autonomy despite dependence". As for the elements that are beyond what fundaments Logotherapy, we could notice dialog fruitful possibilities, because of the discussion about "a-temporal" spiritual life and "objective spirit".

Keywords: Dimensional ontology; Ontological-dimensional anthropology; Logotherapy; Viktor Frankl; Nicolai Hartmann.

\section{Introdução}

A relação de Viktor Frankl com o pensamento filosófico é patente. Licenciado em filosofia em 1949, segundo Xausa (1988, p. 42), Frankl tem sua obra perpassada pela tentativa de esclarecer o que chama de "área limite que se estende entre a psicoterapia e a filosofia", e afirma: "este é o tema principal que está na base de todos os meus trabalhos" (FRANKL, 1990, p. 116-117). Muitos de seus conceitos são marcados por considerações de Max Scheler, Martin Heidegger e Nicolai Hartmann, dentre outros. Quanto a Hartmann, sua clara influência se faz perceber na Antropologia ontológico-dimensional 
proposta por Frankl, além das considerações em torno da temática liberdade - determinismo.

No presente artigo se discute a relação entre o pensamento de Frankl, notadamente a sua Antropologia, e as construções de Nicolai Hartmann. Pareceu oportuno estabelecer alguns pontos de ligação que podem ser úteis para um melhor entendimento de alguns dos conceitos centrais da Logoterapia como, por exemplo, a "dimensão espiritual" e a "liberdade apesar dos condicionamentos". A intenção também é a de encontrar elementos de Hartmann que estão além da apresentação que, via de regra, é feita dele nos círculos ligados diretamente à Logoterapia. Ou seja, espera-se encontrar um Hartmann um pouco além do "Hartmann apresentado por Frankl".

\section{A ontologia dimensional de Nicolai Hartmann}

Hartmann certamente não é um dos filósofos mais conhecidos no cenário acadêmico. No prólogo da segunda edição de uma de suas obras editada em língua espanhola, Ricardo Maliandi (2007, p. 24-25) analisa esse "esquecimento" de Hartmann e aponta dois motivos centrais. Primeiro, ele fala da fascinação provocada pela obra de Martin Heidegger, que, como Hartmann, assimila "critérios metodológicos" da fenomenologia, mas que, também como ele, segue um caminho distinto do campo estritamente fenomenológico. A filosofia de Heidegger está envolvida numa atmosfera "místico-poética", segundo o autor, enquanto Hartmann se inscreve na tradição racionalista. Depois, cita o fato de Hartmann não assumir o chamado giro lingüístico (HARTMANN, 2007, p. 24-25).

Esse esquecimento de Hartmann nos meios acadêmicos não diminui a sua contribuição para o pensamento filosófico e para as ciências sociais. $\mathrm{Na}$ obra de Frankl, por exemplo, a perspectiva da Ontologia hartmanniana se mostra muito presente. A perspectiva lançada por Hartmann de um caráter estratificado do real, a noção de autonomia apesar da dependência e, suas conceituações em torno da vida espiritual, encontram paralelos importantes na proposta frankliana.

\section{O caráter estratificado do real}

Uma clara contribuição do pensamento hartmanniano para a teoria frankliana é a consideração de que o universo possui um caráter estratificado. Mas o que significa isso? A princípio se pode dizer que essa proposta exclui qualquer concepção monista da realidade, por exemplo, a proposta por Skin- 
ner e pelos materialistas em geral, para os quais não há qualquer diferença ontológica entre os conteúdos ditos mentais e o mundo físico material (SKINNER, 2003, p. 19). Para Hartmann, ao contrário, existe uma diferença "evidente" entre a natureza inorgânica e a orgânica, entre o orgânico e o psíquico e entre este e o espiritual (XAUSA, 1988, p. 68).

Xausa $(1988$, p. 69) considera ainda que esta perspectiva do pensamento de Hartmann é fundamental à Psicologia. No entendimento da autora, a Psicologia, em suas mais diferentes vertentes originais (associacionista, fisiologista, reflexologista e comportamental), vinha considerando o humano numa perspectiva parcial, limitada ao plano orgânico, no qual se reduzia o psíquico ao fisiológico. Ainda segundo ela, embora as escolas psicanalíticas tenham explorado e trazido à tona a dimensão do psiquismo, omitiram o plano espiritual, reduzindo este ao psíquico. Assim, apenas na proposta de Hartmann, ainda segundo Xausa (1988), que afirma os diferentes planos do ser, em que se considera uma dimensão espiritual, é que se tem uma visão completa e não reducionista do mundo e do homem.

Para Hartmann (2007) esse caráter estratificado do real era algo indiscutível e passível de ser reconhecido a partir de um olhar mesmo superficial: "o fenômeno inteiro do universo, ainda que seja impenetrável em seu detalhe, mostra o caráter da estratificação de maneira indiscutível e reconhecível já para um olhar superficial" (HARTMANN, 2007, p. 64, tradução nossa ${ }^{1}$ ).

Esta consideração de um caráter de estratificação do universo tem algumas implicações. Hartmann (2007, p. 65-67) aponta três delas: a primeira se refere ao fato de que cada estrato tem suas próprias leis. Não existe estrutura monística e cada estrato precisa ser compreendido a partir de sua própria legalidade. A segunda refere-se à dependência do estrato superior em relação ao inferior, ou seja, "sem natureza material não há vida, sem vida não há consciência e sem consciência não existe mundo espiritual" (HARTMANN, 2007, p. 66, tradução nossa ${ }^{2}$ ). Por fim, o autor se refere ao fato de que a dependência do estrato superior para com o inferior não impede a autonomia.

A dedução que Hartmann (2007) faz dessa consideração acerca das implicações decorrentes do caráter estratificado do real é que existe uma dupla lei de configuração dos estratos: as categorias inferiores são as mais fortes, enquanto as superiores são mais livres. As inferiores são as mais fortes porque independem das superiores e estas, por sua vez, são mais livres pela forma que se dá a relação entre elas, como se verá.

\footnotetext{
$1 \quad$ Texto original: "el fenómeno entero del universo, por muy impenetrable que sea en detalle, muestra el carácter de la estratificación de manera indiscutible y reconocible ya para la mirada superficial."

2 Texto original: "sin naturaleza material no hay vida, sin vida no hay conciencia y sin conciencia no hay mundo espiritual."
} 
Um ponto fundamental se faz necessário ressaltar nesse contexto: Hartmann (2007) tem em vista o "universo real", o mundo, e não o "indivíduo" humano. O problema central hartmanniano na obra citada não é antropológico, mas diz respeito à história. Assim, logo após apresentar esse caráter estratificado do universo, ele afirma que o que vale para o mundo valerá também para a história (HARTMANN, 2007, p. 68). A intenção que se segue a partir daí é mostrar que tanto Hegel como Marx cometeram equívocos semelhantes. Para o autor, Hegel explica unilateralmente os processos históricos a partir da categoria "espírito", ou seja, infringe a lei da força, enquanto Marx, se esforça por captar todo acontecer histórico a partir das relações econômicas estruturantes, infringindo a lei da liberdade. Ambos reduzem assim a complexidade do acontecer histórico, no entendimento de Hartmann (2007).

Por hora, resta explicitar em que estratos Hartmann (2007) concebe que se manifesta o universo real. $\mathrm{O}$ autor deixa claro pelo menos quatro formas ontológicas: o físico-material, o orgânico, o psíquico e o espiritual. A relação que cada estrato do ser estabelece com os demais é característica e será vista em seguida. $\mathrm{O}$ fundamental aqui é que a ênfase recai na pluralidade ontológica do real.

\section{Autonomia apesar da dependência}

A análise que Hartmann (2007) empreende no sentido de perceber como se dá a relação entre os diferentes estratos do ser é significativa para a compreensão acerca da liberdade defendida pela Logoterapia de Viktor Frankl. É exatamente quando analisa essa relação, que surge uma fórmula muito central para a Logoterapia e, notadamente, para o problema liberdade-determinismo. Essa fórmula é utilizada por Frankl de forma exaustiva em sua obra 'Fundamentos Antropológicos da Psicoterapia' (1978) quando discorre acerca do problema do espírito: "autonomia apesar da dependência" (FRANKL, 1978, p. 102).

À dependência já se fez referência acima quando se disse que não existe ser espiritual a não ser aquele que se apoia sobre a dimensão do psíquico. $\mathrm{Da}$ mesma forma não se pode falar em psíquico a não ser o que está apoiado num organismo vivo, e assim por diante. É isso que Hartmann (2007) caracteriza como a dependência dos estrados superiores para com os inferiores. Mas, e a liberdade? Como se configura a liberdade no pensamento hartmanniano?

Hartmann (2007, p. 120) considera que a relação entre o mundo orgânico e o inorgânico ocorre de forma que o primeiro não se reduz ao segundo e a suas leis, ainda que contenha ambas. Ou seja, o organismo vivo está submetido às mesmas leis de qualquer outro corpo físico sem vida (inércia e gravidade, 
por exemplo) e suas células são compostas por átomos da mesma forma que objetos inorgânicos. Ainda que seja mais que tudo isso, o organismo vivo não rompe com as leis que regem o universo material, inorgânico.

Quanto aos estratos superiores (psíquico e espiritual), ocorre algo diferente. $\mathrm{O}$ autor aponta que, se a mesma relação do orgânico com o inorgânico segue em direção aos outros estratos, também o espírito deveria constar de átomos e ter gravidade, mas afirma que aqui começa outro tipo de relação (HARMANN, 2007, p. 120). Também se dá um apoiar-se, portanto uma dependência, mas agora de outro tipo.

A autonomia do psíquico para com o orgânico possui uma magnitude distinta da que tem o orgânico sobre o material. $\mathrm{O}$ exemplo que o autor usa para confirmar esse rompimento do psíquico para com as leis do físico é a espacialidade e tudo que se conecta com ela (HARTMANN, 2007, p. 121). A corporalidade e sua submissão às leis da inércia e da gravidade, por exemplo - válidas quando se tem em vista o organismo vivo e os seres não-vivos - não é válida da mesma forma para com o ser psíquico. A biologia pode falar em uma "mecânica da evolução", mas não há sentido nenhum na psicologia falar em uma "mecânica da percepção". Assim, o autor afirma que as leis da física não podem se manter na psicologia, o que indica um rompimento em relação a essa legalidade própria do físico, seja orgânico ou inorgânico. Há certa liberdade do psíquico para com o orgânico.

Quando se refere ao espiritual, Hartmann (2007, p. 122) afirma que o que vale para o psíquico vale ainda em maior medida para o espiritual, no que diz respeito ao rompimento com as leis dos estratos inferiores. Entre o orgânico e o psíquico ocorre um corte que separa os estratos superiores (psíquico e espiritual) dos inferiores (inorgânico e orgânico) de forma mais radical.

Assim, nessa análise da relação entre os diferentes estratos do ser, que Hartmann (2007) caracteriza como sobreformação e sobreedificação, fica clara a conclusão do autor. Esse rompimento para com as "leis" que regem os estratos inferiores é o indicativo da liberdade crescente das dimensões superiores. Completa-se assim o quadro da autonomia apesar da dependência. A alternativa "ou isso ou aquilo" é ultrapassada por Hartmann (2007) com um "isso apesar daquilo", ou seja, autonomia apesar da dependência.

A título de acréscimo se pode perceber que nessa reflexão acerca do ser espiritual, Hartmann (2007) traz um ponto importante de ser colocado em paralelo com as construções da Logoterapia de Frankl. A vida espiritual aparece aqui como impossível de ser delimitada exclusivamente ao "indivíduo" humano. Embora o espiritual se manifeste no humano na forma de espírito pessoal, ele não o possui de forma privativa: "O característico da vida espiritual é o fato de que os indivíduos não existem, de forma alguma, por si mesmos, tam- 
pouco tem, em absoluto, existência espiritual isolada fora da vida espiritual comum" (HARTMANN, 2007, p. 123, tradução nossa ${ }^{3}$ ).

Hartmann (2007, p. 123) lança um ponto de fixação do seu pensamento que pode servir de reflexão para um paralelo com Frankl. Para o primeiro, não existe vida espiritual isolada num indivíduo pessoal, ainda que aí se manifeste. A vida espiritual não tem uma "existência individualizada", muito pelo contrário, a característica do indivíduo é o nascer e estar lançado num universo comum, num reino espiritual comum que Hartmann (2007) chama de espírito objetivo. O acento que se dá é num "espírito vivente coletivo".

\section{Uma vida espiritual atemporal?}

Outra questão que se quer trazer dentro dessa análise da vida espiritual, a partir dos pontos de vista de Hartmann e Frankl, proposta para esse trabalho, trata-se das considerações deste último em torno da "origem" e "destino" do ser espiritual. Quando Frankl analisa a origem do espírito do ponto de vista ontogenético deixa algo em aberto, o que parece não ser possível de se verificar no pensamento de Hartmann. Ainda que não afirme "de onde vem o espírito", Frankl afirma que "o espiritual deve, portanto, entrar de algum modo, no corpo-alma mas, tão logo isso acontece, ele é envolvido pelo silêncio [...] e assim permanece à espera do momento em que possa manifestar-se" e um pouco a frente, afirma que não se pode dizer de onde vem o espiritual, mas que o certo é que não provém dos cromossomas (FRANKL, 1978, p. 130).

Esta abertura do pensamento de Frankl acompanhada de silêncio acerca de "onde" vem o espírito, se dá também quando ele se questiona sobre o "para onde vai" o espírito, de forma a afirmar que "a saída do espírito no instante da morte de um homem não é menos misteriosa" (FRANKL, 1978, p, 142). De qualquer forma, ele abre uma porta para além do espiritual em seus limites que se podem chamar de "temporais", para questionar acerca de possíveis origens e destinos do espírito, que parecem não passíveis de ser encontrados na teoria hartmanniana.

Em meio a essa reflexão é imperioso notar que Frankl (1978, p. 148) afirma não conhecer nenhuma existência espiritual que seja apartada do psicofísico e que toda separação nesse sentido assume um caráter meramente heurístico. Entretanto, pode-se pensar que essa afirmação não elimina a possibilidade de vida espiritual efetivamente nesse "não-lugar". Ele afirma que é impossível conhecer, mas considera possível e faz uma comparação com a teologia negativa:

3 Texto original: "Lo característico de la vida espiritual es precisamente el hecho de que los individuos no existen de ninguna manera por sí mismos, tampoco tienen en absoluto una existencia real aislada fuera de la vida espiritual común." 
Esta noologia negativa pode afirmar apenas uma coisa sobre a existência da pessoa espiritual para além da sua coexistência com o psicofísico: não é mortal. Esta afirmação negativa - de que a pessoa espiritual é i-mortal não precisa, no entanto, causar-nos espanto. Representa justamente a contrapartida daquela outra afirmação que não se referia à morte, mas à procriação ou ao nascimento, e que era a seguinte: a pessoa é in-criável (FRANKL, 1978, p. 148).

Assim, muito embora não se possa conhecer efetivamente essa existência espiritual para além, ou aquém, do psicofísico, e Frankl não tenha por aí se aventurado, ele não a nega categoricamente. Mais limitado nesse ponto parece ser Hartmann. Se a Frankl coube considerar a possibilidade de vida espiritual "i-mortal”, ainda que impossível de se ter dela conhecimento, a Hartmann incumbe acentuar os limites do conhecimento sem penetrar, todavia, nessas possibilidades. Aliás, Hartmann (2007) até fala de uma vida espiritual "não vivente", mas localiza-a numa forma ontológica específica: no espírito objetivado. Este se referindo às construções socioculturais consignadas nas artes, nas leis e nas demais construções coletivas dos povos.

Quando analisa algumas representações coletivas acerca da vida espiritual, Hartmann (2007) aponta o seguinte: primeiro, considera que temos que ver exclusivamente com o espírito nos limites da experiência, com o que podemos demonstrar ou conhecer, com o que chama de "espírito empírico". Segundo, isso faz com que a vida espiritual seja vista sempre como "ligada ao tempo”. E, terceiro, no campo da experiência não se pode conceber um espírito que paira no ar, mas todo espírito que conhecemos se apoia em algo (HARTMANN, 2007, p. 111).

A despeito dessas diferenças de ênfases, e do campo próprio de conhecimento dos dois pensadores, a influência do pensamento de Hartmann em Frankl é marcante. O que este último faz a partir daí é aplicar de forma específica para o humano essas considerações acerca do caráter estratificado do mundo. Se Hartmann tem em vista o mundo como um todo, nele incluindo obviamente o indivíduo humano em quem se manifesta o espírito pessoal, a Logoterapia de Frankl foca exatamente nessa perspectiva pessoal, obviamente por se tratar de um campo de conhecimento diferente.

\section{A antropologia ontológico-dimensional e sua centralidade na Logoterapia}

Sem desconsiderar a influência significativa da Antropologia de Max Scheler no pensamento frankliano - Scheler que é considerado por alguns como um "pai espiritual" de Frankl (BÖSCHEMEYER, 1990) - o que Frank1 
parece fazer diante dessa visão de Hartmann, do caráter estratificado do real, é aplicá-la especificamente ao humano, usando o termo "dimensão" em detrimento de "estrato", na construção daquilo que ficou conhecido como Antropologia ontológico-dimensional. Para Frankl (1978), o ser humano é essencialmente um ser "pluridimensional". Falando acerca da impossibilidade de reduzir o psíquico ao somático afirma: "não creiam, todavia, que assim a coisa fica resolvida, com a separação entre duas camadas do corpo e da alma. São necessárias mais separações" (FRANKL, 1978, p. 81). É desta influência de Hartmann no pensamento frankliano, dentre outras como já se disse, que deriva a Antropologia ontológico-dimensional característica da Logoterapia.

Nesse contexto pode-se acentuar que Frankl nunca desconsiderou as descobertas das outras abordagens psicológicas, representadas, por exemplo, pela Psicanálise e pelo Behaviorismo. Ainda que possa acusá-las de um reducionismo, reconhece que "no âmbito das respectivas dimensões cada uma dessas escolas tem sua palavra a dizer" (FRANKL, 1989, p. 11). Ele não desconsiderou assim, que o ser humano padecesse dos mais diversos tipos de condicionamentos, exatamente conforme o que se percebe na visão da dependência das dimensões superiores para com as inferiores da Ontologia hartmanniana. Mas o condicionamento não tem a palavra final na sua consideração. É nesse sentido que afirma: "Freud viu certo, no entanto não viu tudo. E ainda generalizou o que viu" (memória do autor).

$\mathrm{Na}$ explanação dessa possibilidade da liberdade apesar dos condicionamentos, vista em Hartmann na fórmula "autonomia apesar da dependência", Frankl (1989) usa uma analogia visual da geometria. Ele apresenta a imagem de um copo que se for tomado em um plano de secção horizontal resultará numa figura circular, portanto num sistema fechado. Entretanto, caso seja tomado em um plano de secção vertical a imagem é de uma figura aberta. E afirma:

\footnotetext{
Qualquer coisa de análogo vale também para o homem. Também ele é às vezes representado como se fosse um sistema fechado [um círculo] no qual agem relações de causa e efeito como reflexos condicionados ou incondicionados. Por outro lado, porém, o ser humano é profundamente caracterizado como um ser aberto à realidade externa (FRANKL, 1989, p. 41).
}

Fica claro que ele concebe como sendo completamente compatíveis o fechamento e a abertura característicos do humano, "o fechamento e a abertura tornaram-se compatíveis entre si. E penso que se dá o mesmo para a liberdade e o determinismo" (FRANKL, 1989, p. 41-42). Foge desta forma, e da mesma forma que Hartmann, da alternativa excludente do "ou isso ou aquilo". 
Assim, os condicionamentos são vistos por Frankl (1989) como algo dado, algo factual, não há possibilidade de não ser condicionado quando nos referimos ao que chama de "plano psicofísico". Nesse âmbito, a contribuição das diferentes escolas de psicoterapia, que partem de um pressuposto determinista, é sempre aceita. A liberdade é vista como uma possibilidade de posicionamento diante das condições psicofísicas, ou seja, "o homem não é livre de certas condições. Mas é livre para tomar posições diante delas" (FRANKL, 1989, p. 42).

Frankl (1989) não se contrapõe à noção de determinação, desde que esta seja vista como algo parcial, como não representando ainda tudo acerca do humano. Então, a que se contrapõe efetivamente Viktor Frankl dentro dessa questão? O que parece claro é que ele não se dispõe a abandonar a noção de unidade na pluralidade característica do humano, e visada no pensamento de Hartmann, ou seja, sua Antropologia ontológico-dimensional é central. E duas correntes de pensamento se chocam frontalmente com essa visão dimensional. O que Frankl chama de "pandeterminismo" e "reducionismo". O primeiro infringe a lei da liberdade, e o segundo esquece da própria pluralidade característica do humano.

\section{Pandeterminismo e reducionismo: desconstruções da pluralidade ontológica}

A noção de liberdade trazida por Frankl (1989), além desta referência básica à Ontologia hartmanniana, dentre outras referências, tem em conta um conceito básico da Logoterapia que trata da capacidade propriamente humana do "autodistanciamento". Frankl (1989, p. 43) afirma que "a liberdade humana implica a capacidade do homem de distanciamento de si próprio." $\mathrm{O}$ autodistanciamento é que possibilita uma atitude a partir de suas condições psicológicas. O problema do pandeterminismo, para Frankl, se dá exatamente porque "a capacidade de autodistanciamento é paralisada pelo pandeterminismo" (FRANKL, 1989, p. 46). Onde, pela capacidade de autodistanciamento e de autotranscendência podem-se ver valores e razões, pelo pandeterminismo sobram apenas causas e efeitos. Na primeira perspectiva têm-se o homem como um ser aberto, na segunda, como um sistema exclusivamente fechado:

Se o homem for tido como um sistema fechado [simplesmente], razões e significados estão excluídos. O que permanece então são causas e efeitos. Os efeitos são representados pelos reflexos condicionados e pelas respostas aos estímulos. As causas são representadas por processos de condicionamento ou pelas pulsões e instintos (FRANKL, 1989, p. 47). 
É clara, para Frankl (1989), a relação entre o que chama de pandeterminismo e o outro ponto que recebe suas críticas nesse contexto, o reducionismo. Ora, defender o pandeterminismo em detrimento da liberdade característica da dimensão espiritual é, não só infringir a lei da liberdade que caracteriza os estratos/dimensões superiores, como reduzir a pluralidade ontológica que o humano manifesta. Seria considerar o homem completamente determinado "a partir de baixo", o que leva a considerar um fenômeno humano numa perspectiva subumana, tal como se pode ver quando se consideram os valores como sendo nada mais que formações de reação e mecanismos de defesa (FRANKL, 1989, p. 51). Esquece-se daquela consideração hartmanniana de que cada estrato tem sua própria legalidade e precisa ser visado a partir disso.

Referindo-se ao comportamento animal e ao comportamento humano, ainda na crítica ao reducionismo, Frankl (1989, p. 50) afirma que os reducionistas não conhecem nenhuma diferença qualitativa entre os dois comportamentos. Essa percepção é facilmente verificável quando se tem em conta que Watson (1913, apud FADIMAN; FRAGER, 1986, p. 191) afirma que "o behaviorista, em seus esforços para conseguir um esquema unitário da resposta animal, não reconhece uma linha divisória entre o homem e a besta". Essa "não divisão", ou "não ruptura" monística, é que representa uma redução da complexidade da existência humana. Onde, aqueles que Frankl considera como reducionistas, veem uma unicidade, ele vê unidade na pluralidade ontológica.

A ideia central do reducionismo psicologista, para Frankl, é a de que o humano se encerra em suas dimensões psíquica e física. Não há uma consideração de uma terceira dimensão: a dimensão espiritual. De forma que Frankl (1964, apud PETER, 1999, p. 16) afirma: "tanto antes como agora, continua acontecendo uma psicologia sem espírito [...] ainda hoje a esfera psicológica representa para inúmeras linhas psicológicas o último círculo da existência humana."

Além dessa perspectiva do reducionismo psicologista, Frankl ainda critica as ideias do reducionismo sociologista, sem deixar de reconhecer aquilo que considera como válido em suas conceituações. Também aqui, não nega que o ser humano seja condicionado socialmente, "toda investigação sobre o condicionamento social - seja de que fenômeno for - tem sentido" (FRANKL, 1978, p. 217). Assim, seriam válidas todas as pesquisas que partissem dessa premissa: "tudo na vida humana é condicionado socialmente" (FRANKL, 1978, p. 217). Mais uma vez o "problema" para Frankl não está em reconhecer o determinismo, mas em permanecer nele.

Sem entrar em pormenores nessa aceitação do "condicionamento social" por parte de Frankl, cumpre apenas considerar que, possivelmente, tal 
consideração, não encontra apoio no esquema da Ontologia dimensional de Hartmann. Dada a intenção do trabalho de encontrar Hartmann para além "do Hartmann que serve de fundamento a Frankl”, é preciso fazer tal ressalva.

A ressalva se dá pelo fato de que aqui, não é a dependência dos estratos inferiores do esquema hartmanniano que é considerada como dependência ou condição, como quando se tem em conta o "psicofísico". Quando Frankl fala em psicofísico, fica claro que a dimensão orgânica e a psíquica podem encontrar sua noção respectiva nas formas ontológicas descritas por Hartmann em sua Ontologia dimensional: o estrato orgânico e o psíquico. Não se dá o mesmo quando se tem em vista uma aceitação do "condicionamento social". Nesse ponto, não há possibilidade de relação com as formas ontológicas de Hartmann. O "social" não representa nenhuma "dimensão inferior" no esquema ontológico hartmanniano. Nesse esquema, as dimensões inferiores, que são as mais fortes, são o físico-material e o orgânico. Delas depende o psíquico e o espiritual.

Para tentar uma aproximação, este condicionamento de ordem social, aceito tacitamente por Frankl, talvez encontre paralelo no conceito de "espírito objetivo" em Hartmann (2007), o que pode sinalizar um distanciamento. O distanciamento se dá porque, seguindo o conceito de espírito objetivo em Hartmann (2007), não haveria que se falar em uma relação de condicionamento ou dependência do homem para com o social. O espírito objetivo é uma dimensão da vida espiritual, portanto, representa o estrato "superior" da Ontologia de Hartmann e é sua dimensão mais evidente: "o espírito objetivo é o mais evidente da nossa vida humana, não o notamos, porque é aí onde vivemos e respiramos constantemente" (HARTMANN, 2007, p. 247, tradução nossa ${ }^{4}$ ).

Em Hartmann (2007), o espírito objetivo, que é analisado detidamente e de forma central, é uma manifestação da vida espiritual, dimensão superior do homem e do mundo. Desta forma, marcada pela liberdade e não pela força de condicionamento característica do físico-material e do orgânico.

É fundamental enfatizar que essa concessão a um "condicionamento social" não é o tom principal das concessões franklianas à noção de determinismo. Frankl se refere bem mais ao condicionamento "psicofísico", sempre caracterizando o homem como um ser que está para além dele, como um ser "bio-psico-espiritual": "o homem é um ser tridimensional. As três dimensões são: somática, psíquica e espiritual” (LUKAS, 1989, p. 28).

Diga-se claramente, que, nenhuma concessão ao determinismo é o tom principal do pensamento de Frankl, isto está presente sim, mas de forma se-

$4 \quad$ Texto original: "el espíritu objetivo es lo más obvio de nuestra vida humana, que no notamos, porque ahí es donde vivimos y respiramos constantemente." 
cundária. A novidade trazida pela Logoterapia para o contexto das psicologias de sua época foi a consideração de uma dimensão espiritual característica do humano e sua liberdade essencial: "não se pode conceber algo que condicione o ser humano a ponto de deixá-lo sem a menor liberdade" (FRANKL, 1991, p. 113). Diga-se mais: "o ser humano não é completamente condicionado e determinado; ele mesmo determina se cede aos condicionantes ou se lhes resiste. Isto é, o ser humano é autodeterminante, em última análise" (FRANKL, 1991, p. 112, grifo do autor).

Voltando à questão da crítica ao reducionismo na perspectiva frankliana, percebe-se que o reducionismo é visto como uma "não-percepção", por parte de algumas perspectivas psicológicas ou sociológicas, da multiplicidade ou pluralidade característica do universo real e, particularmente, do indivíduo humano, trazidas do pensamento hartmanniano. O pandeterminismo e o reducionismo não vêem aquilo que Hartmann considerou que se poderia perceber a partir de um olhar mesmo superficial, ou seja, a pluralidade ontológica do real. É esse um ponto central da teoria de Viktor Frankl.

\section{Considerações finais}

Espera-se que esse diálogo entre Frankl e Hartmann, assumido como proposta para o presente trabalho, tenha trazido pontos de esclarecimento acerca de conceitos fundamentais para a Logoterapia. Percebeu-se que, ainda que ressalte a liberdade da pessoa espiritual, e entende-se que essa foi a grande novidade da Logoterapia de Frankl, o ponto central de seu pensamento, ele não desconsidera os condicionamentos de todas as ordens, particularmente o "psicofísico", tão analisado pelas mais diferentes escolas de psicoterapia. Cada uma delas escolas tem algo a dizer. A autonomia apesar da dependência, a liberdade apesar dos condicionamentos, o fechamento e a abertura característicos do humano, são decorrências da Antropologia ontológico-dimensional de Frankl. É inegável a aproximação em relação a Hartmann e a adesão a uma forma de pensamento que ultrapassa a alternativa excludente do "ou isso" ou "aquilo".

Com a crítica ao pandeterminismo e ao reducionismo, Frankl reafirma sua ligação com a proposta hartmanniana do caráter estratificado do real. O pandeterminismo infringe a lei da liberdade, já o reducionismo simplifica a complexidade do humano. O que Frankl propõe é fundar uma escola terapêutica que reencontre o sentido do humano numa dimensão superior e característica, qual seja, a dimensão espiritual.

Acredita-se também que alguns pontos interessantes surgiram a partir do diálogo. Estes podem servir de base para estudos posteriores. Cite-se nesse 
contexto o conceito de espírito, que encontra contornos diferentes nos dois pensadores, e a questão do "condicionamento social" e do "espírito objetivo".

Acredita-se por fim, que essa aproximação entre o fundador da Logoterapia e uma de suas principais influências no campo filosófico seja fecunda e possa render maiores desdobramentos teóricos e práticos para a Logoterapia, sobretudo, ampliando os pontos de vista a partir daquilo que lhes é comum. É nesse "di-álogo", dentre outros, que se acredita que o pensamento dos dois pode ajudar no estabelecimento de uma Antropologia que faça às vezes de Psicoterapia.

\section{Referências}

BÖSCHEMEYER, U. Fundamentos, diretrizes e métodos de trabalho da logoterapia. In: FRANKL, V., et al. Dar sentido à vida: a logoterapia de Viktor Frankl. Petrópolis, RJ: Vozes, 1990. p. 33-45.

FADIMAN, J.; FRAGER, R. Teorias da personalidade. São Paulo: HABRA, 1986.

FRANKL, V. Fundamentos antropológicos da psicoterapia. Rio de Janeiro: Zahar, 1978.

Um sentido para a vida: psicoterapia e humanismo. Aparecida, SP: Santuário, 1989.

A questão do sentido em psicoterapia. Campinas: Papirus, 1990.

$\overline{\text { Vozes, } 1991 .}$

Em busca de sentido: um psicólogo no campo de concentração. 9. ed. Petrópolis, RJ:

HARTMANN, N. El problema del ser espiritual: investigaciones para la fundamentación de la filosofía de la historia y de las ciencias del espíritu. Buenos Aires: Leviatán, 2007.

LUKAS, E. Logoterapia: a força desafiadora do espírito. São Paulo: Loyola, 1989.

MALIANDI, R. Prefácio. In: HARTMANN, N. El problema del ser espiritual: investigaciones para la fundamentación de la filosofía de la historia y de las ciencias del espíritu. Buenos Aires: Leviatán, 2007. p. 23-40.

PETER, R. Viktor Frankl: a antropologia como terapia. São Paulo: Paulus, 1999.

SKINNER, B. F. Sobre o Behaviorismo. 8. ed. São Paulo: Cultrix, 2003.

XAUSA, I. A. D. M. A psicologia do sentido da vida. 2. ed. Petrópolis: Vozes, 1988.

Submissão em: 30/04/2014

Revisão em: 20/05/16

Aceite em: 21/07/2016 
Revista de Ciências HUMANAS, Florianópolis, v. 50, n. 2, p. 478-491, jul-dez 2016

Daniel Rubens Santiago da Silva é mestrando do programa de pós-graduação em Psicologia da Universidade Federal do Ceará. E-mail: danirubens@hotmail.com

Úrsula Anne Matthias é doutora em Filosofia, professora do Programa de Pós-graduação em Filosofia da Universidade Federal do Ceará.. E-mail: ursula matthias@yahoo.com.br 